Artigo Original

\title{
Ansiedade e desempenho: um estudo com uma equipe infantil de voleibol feminino
}

\author{
Christi Noriko Sonoo ${ }^{1}$ \\ Anderson Luiz Gomes ${ }^{1}$ \\ Mara Laiz Damasceno ${ }^{13}$ \\ Schelyne Ribas da Silva ${ }^{2}$ \\ Mirieli Denardi Limana ${ }^{13}$ \\ ${ }^{1}$ Universidade Estadual de Maringá, Maringá, PR, Brasil \\ ${ }^{2}$ Universidade Estadual do Centro-Oeste, Guarapuava, PR, Brasil \\ ${ }^{3}$ Programa Associado de Pós-Graduação em Educação Física, UEM/UEL, Maringá, PR, \\ Brasil
}

\begin{abstract}
Resumo: O objetivo deste estudo foi analisar a 'ansiedade traço' e 'ansiedade estado' e sua relação com o desempenho pré-competitivo e competitivo no voleibol. O caso estudado foi uma equipe de voleibol feminina infantil. Utilizou-se como instrumentos de medida os protocolos CSAI-II e o SCAT. A coleta de dados ocorreu nos locais de treinamento e durante os Jogos Colegiais 2005. Para a análise dos dados utilizou-se estatística descritiva e o teste " $t$ " de Student. Os resultados indicaram: 'ansiedade traço' précompetitiva e competitiva sem diferenças significativas, porém na 'ansiedade estado' observou-se diferença significativa $(P=0,05)$ para o componente cognitivo. Verificou-se um equilíbrio entre os componentes da 'ansiedade estado' na fase preparatória pelas vitórias em todos os jogos, o que se mostrou diferente na fase competitiva, onde a equipe sofreu duas derrotas. Conclui-se que a ansiedade pode afetar o desempenho das atletas na situação competitiva nesta modalidade e categoria estudada.
\end{abstract}

Palavras-chave: Desempenho atlético. Ansiedade. Voleibol.

\section{Anxiety and performance: a study of an infant female volleyball team}

\begin{abstract}
The objective of this study was to analyze trait anxiety and state anxiety and their relation with pre-competitive and competitive performance in volleyball. The case studied was a infantile female volleyball team. The measure instruments used were the CSAI-II and SCAT protocols. Data collection occurred in training stations and during High School games 2005. Data analysis was performed through descriptive statistics and Student's " $t$ " test. The results indicated: pre-competitive and competitive trait anxiety with no significant differences, however in relation to state anxiety a significant difference was observed $(P=0,05)$ in the cognitive component. A balance was verified between state anxiety components in preparation phase because of the winnings in all games, fact that was different in the competitive phase, where the team lost two times. It is concluded that anxiety can affect athletes' performance in competitive situation in the modality and category studied.
\end{abstract}

Key Words: Athletic performance. Anxiety. Volleyball.

\section{Introdução}

O esporte faz parte da história da humanidade desde os jogos olímpicos da antiguidade que tiveram início na Grécia. No entanto, muitos avanços são verificados ao analisar as competições atuais em que as mais diversas modalidades são prestigiadas pelo nível de performance dos atletas que influenciam as pessoas, independente da fase da vida, a buscar a prática esportiva. As aulas de educação física escolar possibilitam a iniciação ao esporte durante a infância e adolescência, inclusive a participação nos jogos escolares nos quais se observa a presença de competitividade.
Em muitos casos, os jogos escolares vão dando mais ênfase ao aumento do treinamento em busca da melhora do desempenho e, consequentemente, mais títulos e medalhas. $O$ estabelecimento dessas metas gera aumento da cobrança, tanto do professor/técnico como dos próprios alunos/atletas, que muitas vezes por influência de fatores emocionais, tais como ansiedade, stress e medo do erro, não conseguem obter um desempenho satisfatório nas competições (MARGIS et al., 2003; ROSE JUNIOR, 2004).

A ansiedade consiste numa emoção típica do fenômeno stress (SAMULSKI, 2002). Ela é considerada "um estado emocional negativo 
caracterizado pelo nervosismo, preocupação e apreensão associada com ativação ou agitação do corpo" (WEINBERG; GOULD, 2001, p.96). No entanto, a ansiedade pode caracterizar um traço psicológico, chamada de 'ansiedade traço', referindo-se a diferenças individuais relativamente estáveis que levam a percepção de situações ameaçadoras de acordo com as experiências pessoais adquiridas (SPIELBERGER et al., 1979).

As respostas emocionais apresentadas pelos atletas tornaram-se um foco de estudo de grande interesse dentro da psicologia do esporte, impulsionando muitos profissionais a avaliarem as influências da ansiedade em eventos competitivos (HANTON et al., 2004; JONES; UPHILL, 2004). As principais pesquisas focam na verificação dos níveis de ansiedade entre modalidades com características distintas, a relação da ansiedade competitiva e performance, sendo também levada em consideração a experiência em competições, sua relação com outras características psicológicas e inclusive biológicas como o gênero e idade (ABRAHAMSEN et al., 2008; GONCCALVES; BELO, 2007; PENSGAARD; ROBERTS, 2003; CERIN et al., 2000; HANTON et al., 2002).

Baseado em alguns estudos, foi elaborada a teoria da ansiedade traço pré-competitiva que indica uma característica estável e leva a predição do desempenho, mostrando a maneira como o atleta tende a reagir ao detectar ameaças a sua integridade seja ela, física, psíquica ou social (ROSE JUNIOR; VASCONCELLOS, 1997). Além disso, a ansiedade de desempenho no esporte tem sido conceituada como uma predisposição para responder como a adequação do desempenho do atleta em situação competitiva pode ser avaliada através da 'ansiedade estado' cognitiva e somática (GROSSBARD et al., 2007).

As características pessoais, da situação e da tarefa, são fatores que tornam a relação ansiedade-rendimento bastante complexa e diversas hipóteses tentam explicar essa relação. A teoria do Drive aponta que o rendimento resulta da força do hábito e do drive, tido como a ativação fisiológica. No entanto, a teoria afirma que a ativação na fase de aprendizagem gera prejuízos ao rendimento e melhora em indivíduos com maior competência na determinada habilidade (MUCHUANE, 2001). Em seguida, a hipótese do " $U$ " invertido surge como uma alternativa, abordando que a ativação propicia efeitos positivos no desempenho até certo ponto, no entanto sua contribuição tem sido colocada debatida por alguns autores.
Surge, então, uma proposta mais recente e semelhante a esta teoria, sendo denominada teoria da catástrofe do rendimento. Esta teoria postula que níveis de ansiedade acima do ideal, proporcionam um declínio brusco no rendimento, diferente da teoria do "U" invertido, a qual implica em decréscimos gradativos e curvilíneos. A teoria da Zona Ótima de Funcionamento Individual, também surgiu como alternativa a teoria de "U" invertido, sendo a ansiedade relacionada com o rendimento desportivo de cada atleta, onde o rendimento é maximizado variando de atleta para atleta. Assim, alguns atletas com níveis elevados de ansiedade podem alcançar bom desempenho, enquanto outros necessitam estar mais relaxados (MUCHUANE, 2001).

A teoria multidimensional da ansiedade competitiva consiste em um componente cognitivo, que engloba pensamentos e dúvidas sobre o desempenho e a situação competitiva, bem como, o julgamento de si mesmo. O segundo componente consiste numa perturbação somática, que são sensações fisiológicas desagradáveis de excitação como sudorese, batimentos cardíacos e tensão muscular aumentados, inclusive alteração na respiração e frio no estômago; e uma terceira dimensão designada autoconfiança (MARTENS et al., 1990).

Os autores da teoria supracitada apontam que a ansiedade cognitiva relaciona-se de forma linear e negativa com o rendimento e à medida que aumenta a ansiedade cognitiva, o rendimento é afetado. Quanto à ansiedade somática, esta se relaciona de forma curvilínea (em "U" invertido) com o rendimento; e a autoconfiança contribui para a melhoria do rendimento (MARTENS et al., 1990). Estes componentes consistem em uma distinção ampliada de 'ansiedade traço' e 'ansiedade estado' que compõem dois questionários que foram designados mediante a teoria de Spielberger (BIAGGIO, 1999). Martens (1977) e Martens et al. (1990) adaptaram estes questionários para a psicologia do esporte, levando um grande número de pesquisas a identificação do nível de ansiedade traço e estado de atletas visando as questões competitivas (HANTON et al., 2004).

Estas sensações em geral estão relacionadas ao nível de exigência envolvida na situação, como a autocobrança, cobrança do clube, da comissão técnica, companheiros, família, torcida e principalmente ao medo do fracasso frente às exigências do momento vivido pelo atleta. Este medo provoca padrões de respostas emocionais e físicas impróprias à equipe, prejudicando o desempenho do atleta, o qual muitas vezes não 
consegue atuar de maneira satisfatória dando espaços para erros de jogadas ensaiadas, passes imprecisos, falta de visão no jogo, inclusive inibição das capacidades motoras finas e diminuição da capacidade de tomada de decisão (GUZMÁN et al.,1995).

A experiência do atleta de elite permite que estes interpretem seus sintomas de ansiedade com mais facilidade quando comparado a atletas amadores. Assim, a ativação em níveis adequados é muito importante para o jogador no momento do jogo, possibilitando-o alcançar rendimento superior, podendo a ansiedade ser uma fonte essencial para conquistas, desde que identificada e trabalhada adequadamente (JONES et al., 1994).

A questão da ansiedade no esporte pode variar de acordo com a personalidade do praticante, a idade, o sexo e experiência como jogador. Faz-se necessário observar as características psicológicas do atleta em cada fase do treinamento, o momento de determinar objetivos e conteúdos físicos, adaptando-os às exigências que este demanda (WEINECK, 1991).
A prática do voleibol vem crescendo em nosso país e diante da importância de considerar diversos aspectos desta modalidade, este estudo pretendeu ampliar o conhecimento no âmbito da psicologia aplicada ao esporte, tendo em vista a dificuldade de trabalhar com o voleibol visando a obtenção de resultados a curto e médio prazo, inclusive quando necessita-se que o rendimento obtido nos treinamentos se perdure durante as competições. Assim, o objetivo principal deste estudo foi analisar a 'ansiedade traço' e a 'ansiedade estado' e a sua relação com o desempenho pré-competitivo e competitivo em uma categoria infantil de voleibol feminino.

\section{Métodos}

O caso estudado envolveu uma equipe de voleibol feminino da categoria infantil, composta por 9 atletas com idades entre 12 e 14 anos, da cidade de Paiçandu-PR, que participaram dos Jogos Colegiais do Paraná (JOCOP's). A caracterização das atletas encontra-se no quadro 1.

Quadro 1. Característica da amostra composta por adolescentes do sexo feminino praticantes de voleibol da categoria infantil

\begin{tabular}{|c|c|c|c|c|}
\hline Sujeitos & $\begin{array}{l}\text { Idade } \\
\text { (anos) }\end{array}$ & $\begin{array}{l}\text { IIM } \\
\text { (anos) }\end{array}$ & $\begin{array}{c}\text { TPM } \\
\text { (meses) }\end{array}$ & $\begin{array}{c}\text { Títulos } \\
\text { (classificação/ano) }\end{array}$ \\
\hline 1 & 14 & 13 & 5 & $1^{\circ} \mathrm{L}$. JOCOP's Mun./2005 \\
\hline 2 & 14 & 13 & 5 & 1ㄴ․ JOCOP’s Mun./2005 \\
\hline 3 & 14 & 14 & 3 & $3^{\circ} \mathrm{L} . \mathrm{JEP}$ 's/2004, 1ㄴ. JOCOP's Mun./2005 \\
\hline 4 & 13 & 12 & 16 & $1^{\circ} \mathrm{L}$. Civitas, $1^{\circ} \mathrm{L}$. JOCOP's Mun./2005 \\
\hline 5 & 13 & 10 & 37 & 1ㄴ. JOCOP’s Mun./2005 \\
\hline 6 & 13 & 9 & 37 & $3^{\circ} \mathrm{L}$. JEP's/2004, 1ㄴ․ JOCOP's Mun./2005 \\
\hline 7 & 13 & 11 & 20 & 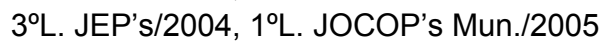 \\
\hline 8 & 12 & 11 & 13 & $2^{\circ}$ L. JEP's/2004, $1^{\circ} \mathrm{L}$. JOCOP's Mun./2005 \\
\hline 9 & 12 & 11 & 18 & 3ㄴ․ JEP's/2004, 1ㄴ. JOCOP's Mun./2005 \\
\hline \multicolumn{5}{|c|}{$\begin{array}{l}\text { IIM: Idade de início na modalidade } \\
\text { TPM: Tempo de prática na modalidade } \\
\text { Civitas: Jogos Escolares de Maringá - PR } \\
\text { JEP's: Jogos Escolares de Paiçandu - PR } \\
\text { JOCOP's Mun.: Fase Municipal dos Jogos }\end{array}$} \\
\hline
\end{tabular}

Como instrumentos de medida foram utilizados dois protocolos: o CSAI - II (Competitive State Anxiety Inventory-2) e SCAT (Sport Competition Trait Anxiety Test).

O primeiro protocolo, CSAI - II tem como objetivo medir a 'ansiedade estado' précompetitiva, ou seja, o quão ansioso o atleta sente-se em um dado momento no tempo, neste caso, logo antes da competição. Divide-se em: ansiedade cognitiva, somática e autoconfiança. $O$ teste é composto de 27 questões, nas quais as respostas podem variar em escalas seguindo: absolutamente não (1); um pouco (2); bastante (3); e muitíssimo (4) (MARTENS et al., 1990).
O SCAT é destinado à identificação do perfil de ansiedade em competição esportiva tendo como objetivo fornecer uma medida de ansiedade-traço competitiva reproduzível e válida de como os atletas ansiosos sentem-se antes de uma competição. É composto por 15 questões e suas respostas variam de: dificilmente (1); às vezes (2) e freqüentemente (3). Sendo que algumas questões têm efeito de ativação, outras de desativação e outras de efeito placebo (MARTENS, 1977).

A pesquisa teve aprovação prévia do Comitê Permanente de Ética em Pesquisa com Seres Humanos, da Universidade Estadual de Maringá, 
sob o parecer nำ117/2006. Após isso, a coleta de dados foi realizada por um dos pesquisadores em duas etapas distintas: na fase preparatória e na fase competitiva. $\mathrm{Na}$ fase preparatória, o teste designado para detectar a ansiedade traço foi aplicado îndividualmente no primeiro dia de treino, quando as atletas retornaram do período de férias. Para obter os dados de 'ansiedade estado' aplicou-se o teste antes de cada jogo amistoso, sempre minutos antes do embarque no ônibus. $\mathrm{Na}$ fase competitiva, $\mathrm{o}$ teste de 'ansiedade traço' foi aplicado antes do embarque do primeiro jogo do campeonato. Os testes de 'ansiedade estado' foram aplicados 15 minutos antes de cada jogo, no próprio ginásio onde realizou-se a competição.

Os dados dos questionários foram agrupados e tratados inicialmente através da estatística descritiva. Após o teste de normalidade Shapiro-
Wilk, realizou-se a comparação dos dados através do teste " $"$ " de Student, adotando de significância estatística de $P \leq 0,05$.

\section{Resultados}

O voleibol é uma das modalidades coletivas que fazem parte do quotidiano escolar, o qual começa a ser praticado por crianças de diversas faixas etárias. Nesta equipe estudada, 4 atletas iniciaram na modalidade entre 12 e 14 anos e o restante entre 9 e 11 anos. Em relação ao tempo de prática do voleibol, 4 atletas tinham entre 1 ano e 1 ano e meio, 3, 6 meses ou menos e a minoria tinha mais de 3 anos de prática.

De acordo com um dos objetivos do estudo, ao comparar a ansiedade traço das atletas, não foi constatada diferença significativa quando levado em consideração as fases preparatória e competitiva (Tabela 1).

Tabela 1. Comparação das médias da 'ansiedade traço' na fase pré-competitiva e competitiva da equipe

\begin{tabular}{cccc}
\hline Fase & Média & DP & $\boldsymbol{P}$ \\
\hline Preparatória & 25,44 & 3,36 & 0,090 \\
Competitiva & 23,22 & 4,21 & \\
\hline DP (Desvio Padrão) & & &
\end{tabular}

Algumas características de comportamentos ansiosos podem ser mensurados de acordo com os pensamentos gerados em relação a competição, inclusive algumas alterações de ordem fisiológica. Na figura 1, encontra-se os valores de 'ansiedade estado' na fase preparatória, nos quais pode-se visualizar índice mais elevado para o componente cognitivo, chegando a cerca de 24 pontos no jogo 3 e 4 . Foi observado também 0 aumento do nível de ansiedade cognitiva e somática a partir do jogo 3 . Isto pode ter ocorrido pelo fato de que a equipe enfrentou adversários com nível tecnicamente superior. Nos jogos 4, 5 e 6 a equipe enfrentou adversários da região, e de acordo com a figura, observa-se um aumento do componente autoconfiança no jogo 4 em relação ao jogo anterior. Nos jogos 5 e 6 houve um declínio dos três componentes da ansiedade em relação aos jogos anteriores ( 3 e 4 ) e a autoconfiança da equipe manteve índices mais estáveis, fato este considerado essencial para os bons resultados da equipe na fase preparatória, que venceu as 6 partidas.

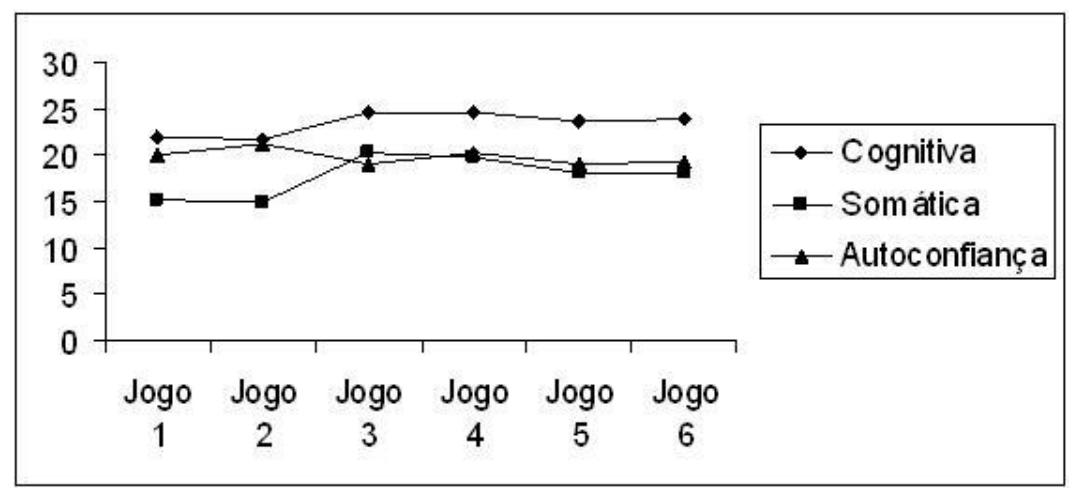

Figura 1. Índices da "ansiedade estado" na fase pré-competitiva 
Tabela 2. Comparação das médias da 'ansiedade estado' na fase pré-competitiva e competitiva

\begin{tabular}{lccccc}
\hline \multirow{2}{*}{$\begin{array}{c}\text { Componentes da } \\
\text { Ansiedade }\end{array}$} & \multicolumn{2}{c}{ Fase Pré-Competitiva } & \multicolumn{2}{c}{ Fase Competitiva } & \multirow{2}{*}{$\boldsymbol{P}$} \\
\cline { 2 - 5 } & Média & DP & Média & DP & \\
\hline Cognitivo & 23,76 & 1,17 & 26,4 & 1,19 & $0,05^{\star}$ \\
Somático & 18,32 & 2,10 & 20,76 & 3,34 & 0,36 \\
Autoconfiança & 19,84 & 0,98 & 18,6 & 0,66 & 0,11 \\
\hline P & & & &
\end{tabular}

$\mathrm{P} \leq 0,05$

DP (Desvio Padrão)

$\mathrm{Na}$ etapa competitiva, o índice dos componentes da 'ansiedade estado' variou consideravelmente em relação à fase preparatória. Observa-se na figura 2, a autoconfiança da equipe manteve-se em um patamar um pouco abaixo (entre 17,7 e 19,4 pontos) quando verificada na fase preparatória (entre 19 e 20,4 pontos - Figura 1). Esse comportamento pode ter sido detectado em decorrência de a equipe ter enfrentado a equipe campeã do ano anterior.

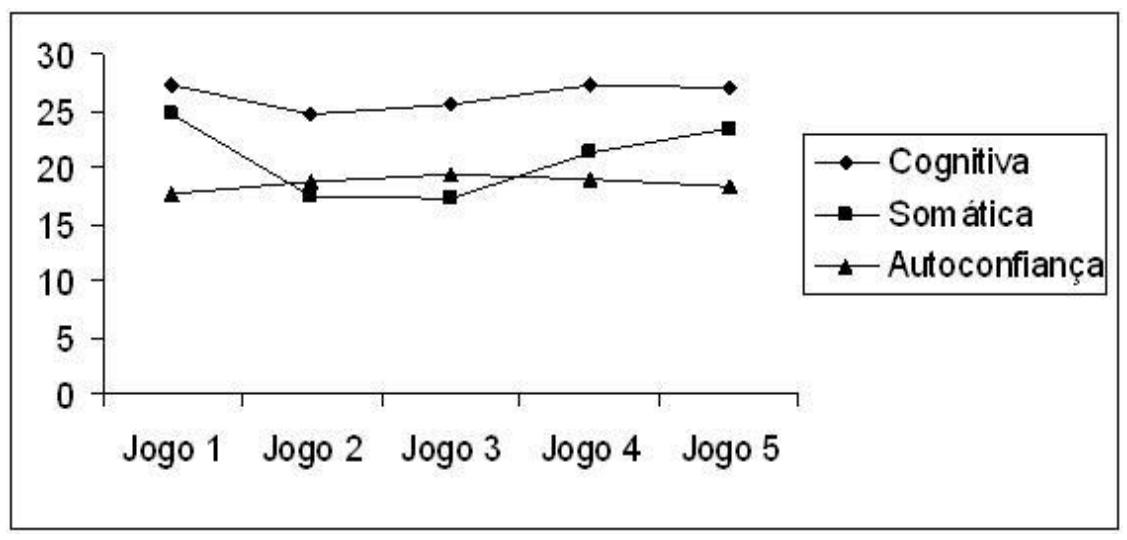

Figura 2. Índices da "ansiedade estado" na fase competitiva

Os escores de ansiedade estado apresentados na tabela 2 revelam que os maiores índices estão relacionados ao componente cognitivo e na fase competitiva estes valores aumentaram enquanto a autoconfiança diminuiu.

\section{Discussão}

De acordo com as características das atletas é possível inferir, em relação ao tempo de prática do voleibol, uma variação de atletas com menos de 6 meses e até acima de 3 anos de experiência. Pode-se observar quanto a idade de início na modalidade, que a maioria das atletas $(55,55 \%)$, iniciaram a prática de voleibol ainda na infância (9 a 11 anos). A literatura apresenta que a idade ideal para se iniciar no voleibol é entre 11 e 12 anos (SUVOROV; CRISHIN, 1990). Assim, os dados confirmam que 4 das atletas que compõem a equipe, começaram a prática nessa faixa etária, o que pode colaborar para que essas atletas tenham melhores condições de apresentar um bom desenvolvimento psicomotor.
Os resultados da comparação da 'ansiedade traço' nas fases pré-competitiva e competitiva podem ser justificados pela própria definição de 'ansiedade traço', considerada uma característica estável e fundamental da personalidade humana (COSTA; BORUCHOVITCH, 2004).

No que se refere às possibilidades de variação do grau de ansiedade frente à competição, esta pode estar atrelada às tarefas exigidas nas modalidades que aplicam resistência e força, as quais têm maior probabilidade de dissipar a ansiedade (MELO, apud SANTOS; PEREIRA, 1997).

Os resultados deste estudo confirmam os achados dos valores médios encontrados para a ansiedade traço em fase competitiva de acordo com uma investigação feita com atletas de diferentes modalidades (judô, atletismo, voleibol e handebol), e em específico para o voleibol. Nesta modalidade verificou-se tanto entre os atletas adolescentes e adultos, níveis médios de ansiedade traço pré-competitiva (de 17 a 23 pontos). Os autores também verificaram diferença 
no nível de ansiedade entre os adolescentes praticantes de esportes coletivos, talvez em função da diferença entre as características dessas modalidades (SANTOS; PEREIRA, 1997).

Na presença de autoconfiança espera-se tanto resultados positivos quanto negativos. É comum cometer alguns deslizes, tomar decisões erradas ou perder a concentração ocasionalmente. Cada indivíduo tem um nível de autoconfiança e por isso, problemas de desempenho podem surgir quando esse componente expressa valores abaixo ou acima do ideal (WEINBERG; GOULD, 2001).

Um estudo desta natureza investigou 78 atletas do sexo feminino e 88 do sexo masculino com idade média de 21 anos de diversas modalidades esportivas individuais (atletismo, judô, ginástica e tênis de mesa) e coletivos (basquetebol, futebol, handebol e rúgbi). Os autores destacam a importância de considerar todas as dimensões da ansiedade simultaneamente, visto que, os subgrupos de atletas diferiram significativamente em perturbações de concentração, ansiedade traço, perturbações somáticas, preocupação com erros, percepção da pressão dos pais, e intensidade e freqüência de autoconfiança (MARTINENT: FERRAND, 2007).

Em uma equipe de atletas de voleibol em fase escolar da cidade de Ponta Grossa (PR), com idade entre 15 e 17 anos de ambos os gêneros, os autores verificaram que grande parte dos atletas possuía um nível médio de ansiedade estado (17-23 pontos) e em menores proporções, ansiedade média-alta (24-27 pontos). No entanto, os pesquisadores não indicam se os testes foram aplicados em fase preparatória ou competitiva (APLEWICZ et al., 2009). Porém os resultados de ambos estudos se encontram similares, estando a 'ansiedade estado' pré-competitiva e competitiva, de um modo geral, dentro dos limites de ansiedade considerada média.

$O$ fato do componente autoconfiança ter apresentado índices inferiores na fase competitiva pode ter sido em decorrência do confronto da equipe estudada com a equipe campeã do ano anterior. Por outro lado, os níveis de ansiedade cognitiva e somática começaram altos, bem acima do verificado na fase précompetitiva, provavelmente pela angústia da estréia na fase competitiva, que resultou em derrota por 2 sets a 0 .

Além disso, foi possível constatar que quando a equipe apresentou níveis médios de ansiedade cognitiva e somática, ocorreram as vitórias (jogos 2, 3 e 4), e quando estes alcançaram níveis de ansiedade mais altos (por volta de 27 pontos para cognitiva e 24 pontos para a somática) ocorreram as derrotas (jogos 1 e 5 ). Diante desses resultados observados pode-se enfatizar que a percepção do desafio e sua relação com a percepção de capacidade do atleta podem levar ao excesso de ansiedade e consequentemente, impedir que 0 atleta atue com seu melhor desempenho (STEFANELLO, 2007). No caso desta equipe de voleibol notou-se frente aos jogos de menor importância, níveis de ansiedade consideravelmente mais baixos, mas quando o jogo era considerado de maior importância, os níveis de ansiedade também aumentavam.

Quanto ao componente autoconfiança, este apresentou valores menores na fase competitiva em relação à preparatória, enquanto o nível do componente cognitivo e somático aumentaram devido à baixa confiança da equipe, podendo ter sido este o motivo que levou derrota da equipe nos jogos 1 e 5 da competição.

Em um grupo de jogadoras universitárias de voleibol (18 a 22 anos) foi analisada a ansiedade pré-competitiva a fim de testar a teoria de zona ótima de funcionamento individual em um esporte coletivo. Os autores detectaram que as atletas da equipe de voleibol apresentam variação ótima de ansiedade pré-competitiva. Conforme esta teoria, as atletas foram capazes de prever com precisão a ansiedade antes de uma partida difícil, com maior probabilidade de ter níveis de ansiedade dentro dos parâmetros postulados (RAGLIN; MORRIS, 1994).

$\mathrm{Na}$ verificação da ansiedade-traço competitiva frente ao gênero, faixa etária, experiência em competições e tipo de modalidade esportiva (individual e coletiva), foram avaliados 105 atletas jovens com idades variando de 11 a 20 anos e a maioria do sexo masculino. Os resultados indicaram que as mulheres apresentaram maior ansiedade-traço competitiva do que os homens, não relatando diferença significativa para as demais variáveis estudadas (GONCALVES; BELO, 2007). Na literatura, estudos apontam que as mulheres respondem com maior intensidade do que os homens às situações desportivas competitivas, possibilitando maiores índices de ansiedade no sexo feminino por ser mais sensível (LAWTHER, 1978).

$\mathrm{Na}$ natação, um estudo avaliou os níveis de ansiedade pré-competitiva de atletas em competições estaduais e regionais e detectaram que todos os atletas apresentaram um bom nível de autoconfiança independentemente do nível da competição. Além disso, as mulheres apresentaram uma tendência para serem mais 
ansiogênicas que os homens (BARBACENA; GRISI, 2008).

Outro estudo realizado com nadadores amadores investigou as diferenças na intensidade e direção do estado de ansiedade competitiva e autoconfiança entre grupos com alto e baixo uso de habilidade psicológica. De acordo com os resultados, verificaram-se diferenças significativas, indicando que nadadores amadores utilizam principalmente estratégias de relaxamento para reduzir e interpretar seus níveis de ansiedade (FLETCHER; HANTON, 2001).

Levando em consideração a ansiedade frente a competições, a relação entre os níveis de ansiedade e o desempenho esportivo de mesatenistas de ambos os gêneros foi investigada após uma competição classificatória e os autores verificaram que os atletas se sentiram mais ansiosos nos momentos decisivos e de maior importância no torneio. Além disso, relataram que os finalistas da competição utilizaram de técnicas mistas (cognitivas e somáticas) para controlar a ansiedade e classificaram seu desempenho como esperado ou melhor (IIZUKA et al.; 2005).

É importante ressaltar os achados que apontam atletas que se esforçam para a perfeição e controlam as reações negativas para a imperfeição, podem sofrer menos ansiedade e mais autoconfiança até mesmo durante as competições (STOEBER et al., 2007).

Ao comparar as médias da 'ansiedade estado' entre as fases observou-se uma diferença estatisticamente significativa apenas para 0 componente cognitivo. No entanto, entre o componente somático e autoconfiança não foi verificada diferença estatisticamente significativa, porém, o componente somático se elevou enquanto a autoconfiança diminuiu em pequenos índices.

Diante disso, distinguir entre ansiedade cognitiva e somática pode ser útil, uma vez que foi demonstrado que estes possuem diferentes antecedentes, e que as expectativas de desempenho realizada antes da avaliação estão mais correlacionadas com o estado cognitivo do que a ansiedade somática (KOIVULA et al., 2002).

Os valores encontrados para os componentes de ansiedade na fase preparatória e competitiva, corroboram com os resultados do estudo que verificou a ansiedade pré-competitiva frente aos resultados de jogos de futsal de equipes juvenis e adultas, e encontrou médias menores de ansiedade cognitiva pré-competitiva entre as equipes vitoriosas. Para o fator autoconfiança não houve diferenças estatísticas significativas (HERNANDEZ; GOMES, 2002).

Não obstante, cumpre ressaltar que os resultados permitiram alcançar os objetivos propostos, identificando inicialmente o nível de ansiedade traço e estado, durante as duas fases da competição. Assim, foi possível concluir que a ansiedade traço manteve-se estável, provavelmente por fazer parte da personalidade das atletas. Com relação à 'ansiedade estado', esta apresentou alterações significativas, principalmente no componente cognitivo, em que a equipe apresentou mais preocupações com seu desempenho na fase competitiva.

Ao avaliar o resultado da equipe na competição e comparar com os níveis de ansiedade, verificou-se que o equilíbrio entre os componentes de ansiedade resultou na vitória da equipe na fase preparatória. Por outro lado, o aumento considerável dos níveis de ansiedade nos componentes cognitivo e somático e a diminuição no componente autoconfiança trouxeram um resultado competitivo negativo a equipe.

Conclui-se que a ansiedade pode afetar 0 desempenho esportivo de jovens atletas da modalidade de voleibol, confirmando as teorias de estudos anteriores. Entende-se, dessa forma, que para obter resultados positivos é fundamental que os atletas e técnicos conheçam o seu estado ansioso e saibam como lidar com suas emoções no momento da competição. Com isso, lidar com a ansiedade e buscar a melhor performance, são aspectos importantes que tendem a ser facilitados quando utiliza-se de meios, tais como a psicologia esportiva para que a confiança e motivação transmitidos durante a fase précompetitiva possam surtir resultados também durante a competição.

Diante disso, sugere-se que novas pesquisas sejam realizadas, inclusive acompanhando o desempenho de equipes em torneios de diferentes níveis, para que fatores psicológicos como a ansiedade seja avaliada de acordo com o rendimento individual dos atletas. Assim, a partir deste conhecimento torna-se possível garantir resultados mais satisfatórios, desde que os atletas sejam beneficiados de acordo com suas necessidades.

\section{Referências}

ABRAHAMSEN, F. E.; ROBERTS, G. C.; PENSGAARD, A. M. Achievement goals and gender effects on multidimensional anxiety in national elite sport. Psychology of Sport and Exercise, v. 9, p. 449-464, 2008. 
http://dx.doi.org/10.1016/j.psychsport.2007.06.005

APLEWICZ, J. G. F.; ECAVE, C.; GOMES, H. A.; LIMA, H. H.; LAURINDO, M. A.; JUNIOR, G. B. V. Níveis de ansiedade em atletas escolares de voleibol de faixa etária de 15 a 17 anos. Revista do Centro de Pesquisas Avançadas em Qualidade de Vida, v. 1, n. 1, 2009. Disponível em:

http://www.guanis.org/cpaqv/1/rcpaqv vol01 200 9 joao aplewicz.pdf. Acesso em: 20 nov. 2008.

BARBACENA, M. M.; GRISI, R. N. F. Nível de ansiedade pré-competitiva em atletas de natação. Conexões, Revista da Faculdade de Educação Física da UNICAMP, Campinas, v. 6, n. 1, 2008. Disponível em:

http://polaris.bc.unicamp.br/seer/fef/viewarticle.ph p?id=266. Acesso: 24 out. 2009.

BIAGGIO, A. M. B. Ansiedade, raiva e depressão na concepção de C. D. Spielberger. Revista de Psiquiatria Clínica, v. 25, n. 6, 1999. Disponível em: http://www.hcnet.usp.br/ipq/revista/. Acesso em: 25 set.09.

CERIN, E.; SZABO, A..; HUNT, N.; WILLIAMS, C.. Temporal patterning of competitive emotions: a critical review. Journal of Sports Sciences, v. 18 , p. 605-625, 2000.

http://dx.doi.org/10.1080/02640410050082314

COSTA, E.R.; BORUCHOVITCH, E. Compreendendo Relações entre Estratégias de Aprendizagem e a Ansiedade de Alunos do Ensino Fundamental de Campinas. Psicologia:

Reflexão e Crítica, v. 17, n.1, p. 15-24, 2004. Disponível em:

http://www.scielo.br/pdf/prc/v17n1/22301.pdf. Acesso em: 24 out. 2009.

FLETCHER, D.; HANTON, S. The relationship between psychological skills usage and competitive anxiety responses. Psychology of Sport and Exercise, v. 2, p. 89-101, 2001. http://dx.doi.org/10.1016/S1469-0292(00)00014-5

GONÇALVES, M. P.; BELO, R. P. Ansiedadetraço competitiva: diferenças quanto ao gênero, faixa etária, experiência em competições e modalidade esportiva em jovens atletas. PsicoUSF, v. 12, n. 2, p. 301-307, 2007. Disponível em: http://pepsic.bvs-

psi.org.br/pdf/psicousf/v12n2/v12n2a18.pdf. Acesso em: 24 out. 2009.

GROSSBARD, J. R.; CUMMING, S. P.; STANDAGE, M.; SMITH, R. E.; SMOLL, F. L. Social desirability and relations between goal orientations and competitive trait anxiety in young athletes. Psychology of Sport and Exercise, v. 8, p. 491-505, 2007.

http://dx.doi.org/10.1016/j.psychsport.2006.07.009
GUZMÁN, J. I. N.; AMAR, J. R; FERRERAS, C. G. Ansiedad pré-competitiva y conductas de autocontrol en jugadores de futbol. Revista de Psicología del Deporte, v.7, n. 8, p. 7-17, 1995.

HANTON, S.; MELLALIEU, S. D.; HALL. R. Reexamining the competitive anxiety trait-state relationship. Personality and Individual Differences, v. 33, p. 1125-1136, 2002. http://dx.doi.org/10.1016/S0191-8869(02)00003$\underline{x}$

HANTON, S.; THOMAS, O.; MAYNARD, I. Competitive anxiety responses in the week leading up to competition: the role of intensity, direction and frequency dimensions. Psychology of Sport and Exercise, v. 5, p. 169-181, 2004. http://dx.doi.org/10.1016/S1469-0292(02)00042$\underline{0}$

HERNANDEZ, J. A. E.; GOMES, M. M. Coesão grupal, ansiedade pré-competitiva e o resultado dos jogos em equipes de futsal. Revista

Brasileira de Ciência do Esporte, v. 24, n. 1, p. 139-150, 2002. Disponível em:

http://www.rbceonline.org.br/revista/index.php/RB CE/article/view/347/302. Acesso em: 24 out. 2009.

IIZUKA, C.A.; DANTAS, L.E.P.B.T.; MACHADO, A.A.; MARINOVIC, W. Controle da ansiedade em mesa-tenistas e a sua relação com o desempenho esportivo. Revista Mackenzie de Educação Física e Esporte, v. 4, n. 4, p. 127135, 2005. Disponível em:

http://www3.mackenzie.br/editora/index.php/remef larticle/viewFile/1313/1029. Acesso em: 24 out. 2009.

JONES, M. V.; UPHILL, M. Responses to the Competitive State Anxiety Inventory-2(d) by athletes in anxious and excited scenarios.

Psychology of Sport and Exercise, v. 5, p. 201212, 2004. http://dx.doi.org/10.1016/S1469$\underline{0292(02) 00054-7}$

JONES, G.; HANTON, J.; SWAIN, A. Intensity and interpretation of anxiety symptoms in elite and nonelite performers. Personality and Individual Differences, v. 17, p. 657-663, 1994. http://dx.doi.org/10.1016/0191-8869(94)90138-4

KOIVULA, N.; HASSME'N, P.; FALLBY, J. Selfesteem and perfectionism in elite athletes: effects on competitive anxiety and self-confidence.

Personality and Individual Differences, v. 32, p. 865-875, 2002. http://dx.doi.org/10.1016/S01918869(01)00092-7

LAWTHER, J. D. Psicologia Desportiva. 2. ed. Rio de Janeiro: Fórum, 1978.

MARGIS, R.; PICON, P.; COSNER, A. F.; SILVEIRA, R. O. Relação entre estressores, 
estresse e ansiedade. Revista de Psiquiatria do

Rio Grande do Sul, v. 25, n. 1, p.65-74,

2003. http://dx.doi.org/10.1590/S0101-

81082003000400008

MARTENS, R. Sport competition anxiety. $2^{\mathrm{a}} \mathrm{ed}$. Illinoi: Human kinetics Publishers, 1977.

MARTENS, R.; VEALLEY, R.S.; BURTON, D. Competitive anxiety in sport. Champaign, Human Kinetics, 1990.

MARTINENT, G.; FERRAND, C. A cluster analysis of precompetitive anxiety: Relationship with perfectionism and trait anxiety. Personality and Individual Differences, v. 43, p. 1676-1686, 2007.

http://dx.doi.org/10.1016/j.paid.2007.05.005

MUCHUANE, D. V. Estudo da ansiedade précompetitiva em atletas moçambicanos de Natação e Atletismo. 2001. 96 f. Dissertação (Mestrado em Ciência do Desporto) - Faculdade de Ciências do Desporto e de Educação Física, Universidade do Porto, 2001. Disponível em: http://repositorio.up.pt/aberto/bitstream/10216/975 3/3/4918 TM 01 P.pdf. Acesso em: 26 out. 2009.

PENSGAARD, A. M.; ROBERTS, G. C. Achievement goal orientations and the use of coping strategies among Winter Olympians.

Psychology of Sport and Exercise, v. 4, p. 101116, 2003. http://dx.doi.org/10.1016/S14690292(01)00031-0

RAGLIN, J. S.; MORRIS, M. J. Precompetition anxiety in women volleyball players: a test of ZOF theory in a team sport. British Journal of Sports Medicine, v. 28, n. 1, 1994. Disponível em: http://www.ncbi.nlm.nih.gov/pmc/articles/PMC133 2158/pdf/brismed00013-0049.pdf. Acesso em: 24 out. 2009.

ROSE JUNIOR, D. D. Situações de jogo como fontes de "stress" em modalidades esportivas coletivas. Revista Brasileira de Educação Física e Esportes, v. 18, n. 4, p. 385-395, 2004.

ROSE JUNIOR, D. D.; VASCONCELLOS, E. G. Ansiedade-traço competitiva e atletismo: um estudo com atletas infanto-juvenis. Revista Paulista de Educação Física, v. 11, n. 2, p. 148154, 1997. Disponível em:

http://www.usp.br/eef/rpef/v11n2/v11n2p148.pdf. Acesso em: 24 out. 2009.

SAMULSKI, D. Psicologia do Esporte. São Paulo: Manole, 2002.

SANTOS, S. G.; PEREIRA, S. A. Perfil do nível de ansiedade-traço pré-competitiva de atletas de esportes coletivos e individuais do estado do Paraná. Movimento, v. 4, n. 6, p. 3-13, 1997.
Disponível em:

http://www.seer.ufrgs.br/index.php/Movimento/arti cle/view/2238/944. Acesso em: 24 out. 2009.

SPIELBERGER, C. D.; GORSUCH, R. L.; LUSHENE, R. E. Inventário de ansiedade traçoestado IDATE - Manual. Trad. e adaptação Ângela Biaggio. Rio de Janeiro: CEPA, 1979.

STEFANELLO, J. Situações de estresse no vôlei de praia de alto rendimento: um estudo de caso com uma dupla olímpica. Revista Portuguesa de Ciência do Desporto, v. 7, n. 2, p. 232-244, 2007. Disponível em:

http://www.fade.up.pt/rpcd/ arquivo/artigos soltos /vol.7 nr.2/1-11.pdf. Acesso em: 24 out. 2009.

STOEBER, J.; OTTO, K.; PESCHECK, E.; BECKER, C.; STOLL, O. Perfectionism and competitive anxiety in athletes: Differentiating striving for perfection and negative reactions to imperfection. Personality and Individual Differences, v. 42, p. 959-969, 2007. http://dx.doi.org/10.1016/j.paid.2006.09.006

SUVOROV, Y. P.; GRISHIN, O. N. Voleibol iniciação. Rio de Janeiro, Sprint, 1990.

WEINBERG, R. S.; GOULD, D. Fundamentos da psicologia do esporte e do exercício. Porto Alegre: Artmed editora, 2001.

WEINECK, J. Biologia do esporte. São Paulo: Manole, 1991.

Endereço:

Mara Laiz Damasceno

Rua São João, 288, ap. 12, Zona 07

Maringá PR Brasil

87.030-200

Telefone: (44) 9135-0350

e-mail:mara_laiz@yahoo.com.br

Recebido em: 10 de novembro de 2009.

Aceito em: 29 de abril de 20010.

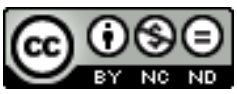

Motriz. Revista de Educação Física. UNESP, Rio Claro, SP, Brasil - elSSN: 1980-6574 - está licenciada sob Licenca Creative Commons 